\title{
Authorship trends in the Egyptian orthopedic journal (from 2012 to 2020), as an example of a specialized Egyptian medical journals
}

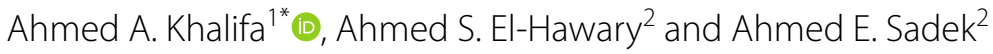

\begin{abstract}
Background: Authorship trends in medical journals were studied in many disciplines, mostly in western countries' journals. We aimed at studying the authorship trends in the Egyptian Orthopaedic Journal as an example of a specialized Egyptian medical journal.

Results: A total of 397 articles were eligible for analysis. The mean number of authors per article was $2 \pm 1$ (range from 1 to 6), 161 (40.6\%) articles were single authorship. The degree of the first author was reported in 305 (76.6\%), the first author carried an M.D. degree in 302 (99\%) articles, and in three (1\%), the first author carried a master's degree. No authors with a bachelor's degree were reported. Forty-two institutions contributed to the publications, 14 (33.3\%) international and 28 (66.7\%) Egyptian national institutions. In 368 (92.7\%) articles, all the authors were from the same institution, and 29 (7.3\%) articles were published as a cooperation between different institutions with a mean $1.1 \pm 0.3$ institution per article. International contribution to the journal was found in 21 (5.3\%) articles. The orthopedic department from Cairo university was the most contributing department to the journal publications.

Conclusions: The old trend of single authorship prevails in the journal publications with a notable deficiency in young researchers' contribution to the journal and low incidence of international contribution and poor national institution cooperation.
\end{abstract}

Keywords: Bibliometric, Egyptian Orthopaedic Journal, Authorship, Medical journals

\section{Background}

Evaluation of the bibliometric characteristics such as authors' numbers and their affiliations had been a concern in various studies in different medical and scientific fields (Chow et al. 2015; Dotson et al. 2011; Tilak et al. 2015). Many of these studies reported a trend of increase of authors numbers per article and a notable increase in the international groups' contributions in various journals over the past 20 years (Camp and

\footnotetext{
*Correspondence: ahmed_adel0391@med.svu.edu.eg

${ }^{1}$ Orthopaedic and Traumatology Department, Qena Faculty of Medicine

and University Hospital, South Valley University, Qena, Egypt

Full list of author information is available at the end of the article
}

Escott 2013; Cvetanovich et al. 2015; Reich et al. 2014). The increased demand for publishing to get a promotion with the added complexity of the research subjects was among the reasons behind the change in the authorship trends, especially the numbers of authors per article and the cooperation between different specialties as well as the creation of multinational research groups (Chow et al. 2015; Dotson et al. 2011). The engagement of young researchers (medical students and residents) in the publication process and authorship had been an important issue discussed in many reports (Al-Busaidi 2015; Lehman et al. 2017; Schrock et al. 2016), in a study by Al-Busaidi and Al-Shaqsi (2015) to evaluate the medical 
students' contributions in the new Zealand Medical Journal over 14 years, they found that students' contributions increased with time, nearly tripled in 2013 when compared with their contribution in 2000, which reflects more incorporation of students in the medical research activities.

To the best of our knowledge, trends in authorship characteristics have not been thoroughly investigated in surgical medical journals originating from Egypt. The purpose of this study was to evaluate the authorship, affiliation, article types, and international contribution trends by examining publications from the Egyptian Orthopaedic Journal (EOJ) in the period from 2012 to 2020 as an example of specialized Egyptian medical journals.

\section{Methods}

The Egyptian Orthopaedic Journal (EOJ) is the official journal of the Egyptian Orthopaedic Association (EOA) (http://www.eoj.eg.net/aboutus.asp); it is an open-access peer-reviewed journal, published quarterly. Articles published in EOJ from 2012 to 2020 were reviewed from the journal's archive (http://www.eoj.eg.net/backissues.asp). Editorials, letters to the editor, questions bank articles, and book chapters were excluded. For each article, two of the authors evaluated the following, number of the authors contributed to the article, the academic degree(s) held by the first author (or their Egyptian equivalent) and the higher degree was reported, the country of the institution to which the author(s) are affiliated, the number of institutions contributing to the article. The address mentioned for the authors was used to determine where the work was performed and to categorize the author groups as national or international. National institutions were classified into a university hospital-related (academic centers) or a governmental hospital related. The articles were classified into sub-specialties according to the subject it is covering; we grouped the specialties into general orthopedics (including oncology and deformity correction surgery, etc.), arthroplasty, foot and ankle, hand and micro-surgery, spine, pediatric, sports medicine, and trauma surgery. For articles in which data in question were missed, we contacted the corresponding author by email to obtain this information.

Descriptive statistics were reported as the mean and standard deviation (mean \pm S.D.), numbers, and percentages $[\mathrm{n}(\%)]$. The range was reported when mentioning was beneficial.

\section{Results}

The last update of the journal Archive contained 416 articles, of which 397 were eligible for analysis (after applying the exclusion criteria). The mean number of authors per article was $2 \pm 1$ (range from 1 to 6 ), and articles written by a single author were $161(40.6 \%)$, representing the majority (Fig. 1).

The degree of the first author was not reported in 93 (23.4\%) articles; in the remaining $305(76.6 \%)$ articles where the degree was reported, the first author carried an

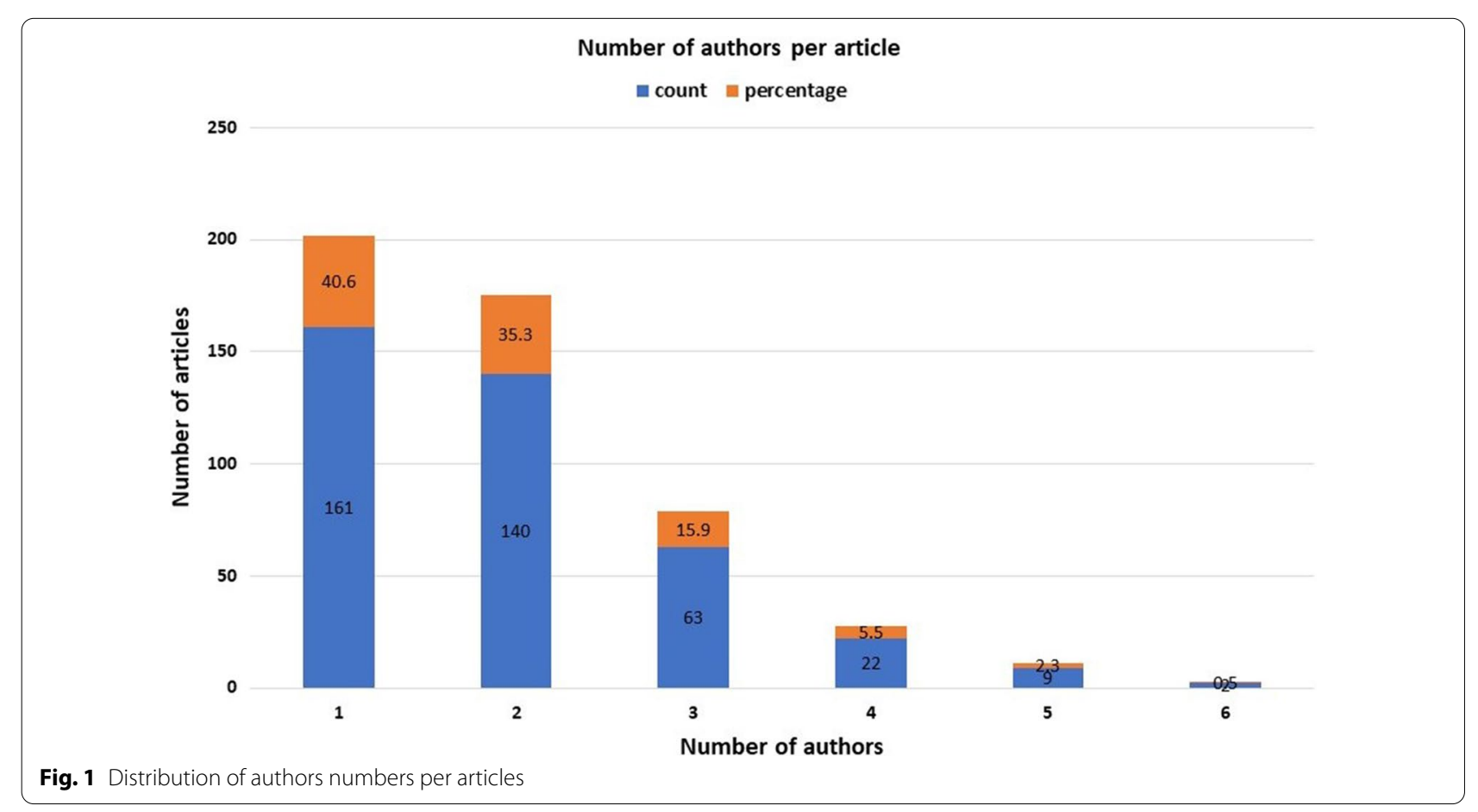


M.D. degree in 302 (99\%) articles and in three (1\%) articles the first author carried a master degree. No authors with a bachelor's degree were found, and the last author's degree was not reported in any article. A total of 42 institutions contributed to the articles published in the studied period, 14 (33.3\%) international institutions, and 28 (66.7\%) national Egyptian, which were divided as follows: 19 university hospitals (academic centers), seven governmental hospitals, and two non-orthopedic institutions. In $368(92.7 \%)$ articles, all the authors were affiliated to the same institution, and $29(7.3 \%)$ articles were published as cooperation between more than one national institution with a mean $1.1 \pm 0.3$ institution per article. The top 10 contributing institutions were all academic centers (Fig. 2), with the orthopedic department from Cairo university taking the lead for the articles published solely by authors affiliated to it and as a contributor with other institutions. International contribution to the journal was found in 21 (5.3\%) articles; in seven (1.8\%) articles, the contribution was represented as an author affiliated to an international institution besides other authors from a national institute. In 14 (3.5\%) articles, all the authors were affiliated with an international institution (international group).

Regarding the types of research articles, original articles were 394 (99.2\%) representing most published articles and three $(0.8 \%)$ case reports. The articles classification, according to sub-specialty, are shown in
(Fig. 3) with the articles written on trauma 113 (28.5\%) accounted for the commonest type.

\section{Discussion}

Performing bibliometric studies is essential for monitoring the improvement and qualities of scientific research by specific journals or medical communities (Dynako et al. 2020). Studies investigating the trends of authorship are now becoming popular among different medical and surgical specialties (Khalifa et al. 2021; Russell et al. 2019; Zeinoun et al. 2020), many reports from orthopedic (Camp and Escott 2013; Schrock et al. 2016) neurosurgery (Emery 2019), plastic surgery (Rifkin et al. 2020), radiology (Chow et al. 2015), and cardiology (Amankwah et al. 2018) have been published.

Participation in scientific articles publication is vital for increasing the score during the competition over residency and fellowship positions for junior researchers and its importance for academic development and promotion for senior researchers (Dynako et al. 2020; Stain et al. 2013).

The critical findings of the current study are the significant deficiency in the international institutions' contribution to the journal; no young researchers were contributing to the authorship, the lack of scientific production from governmental hospitals, and a deficiency in cooperation between national institutions.

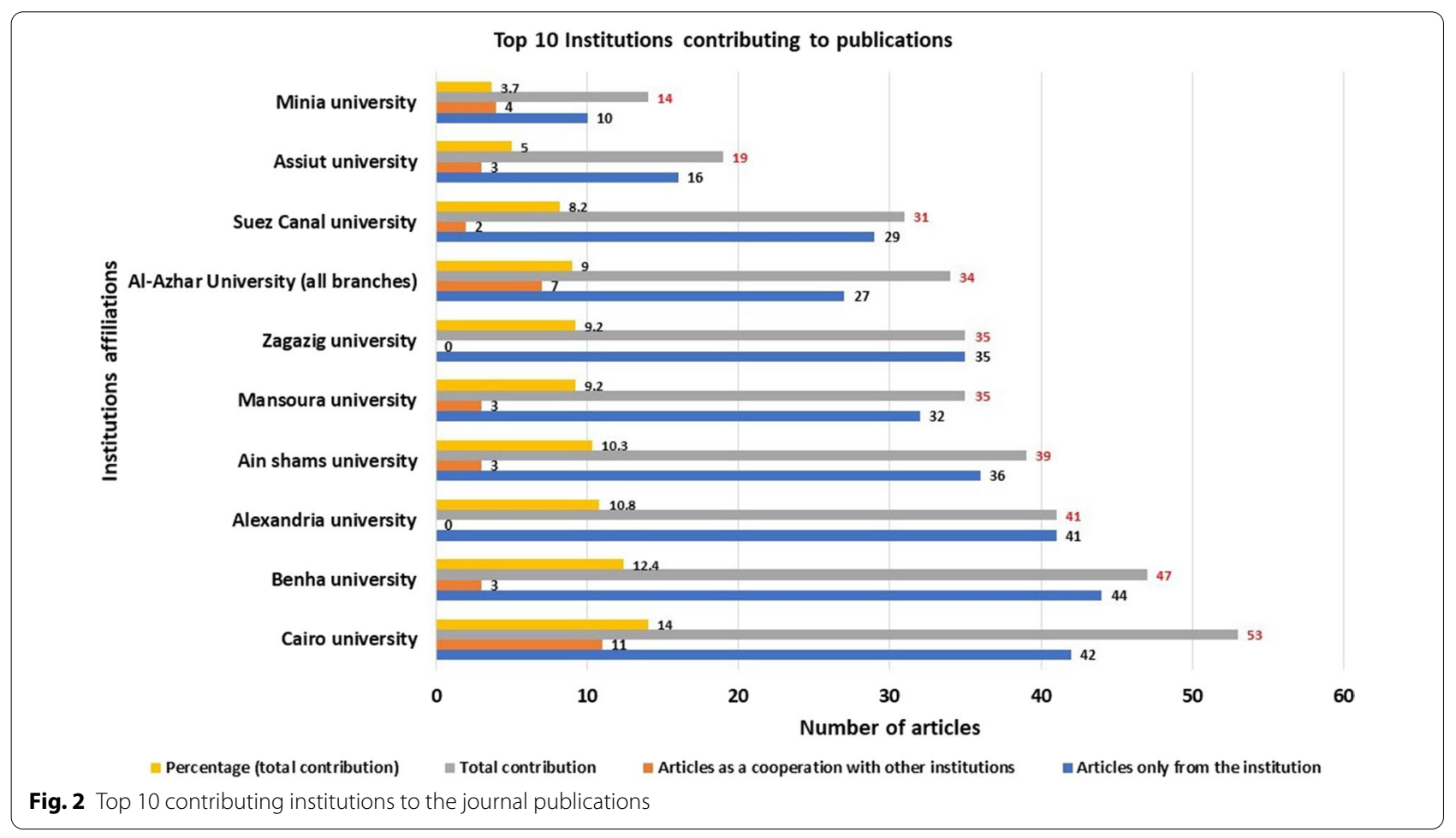




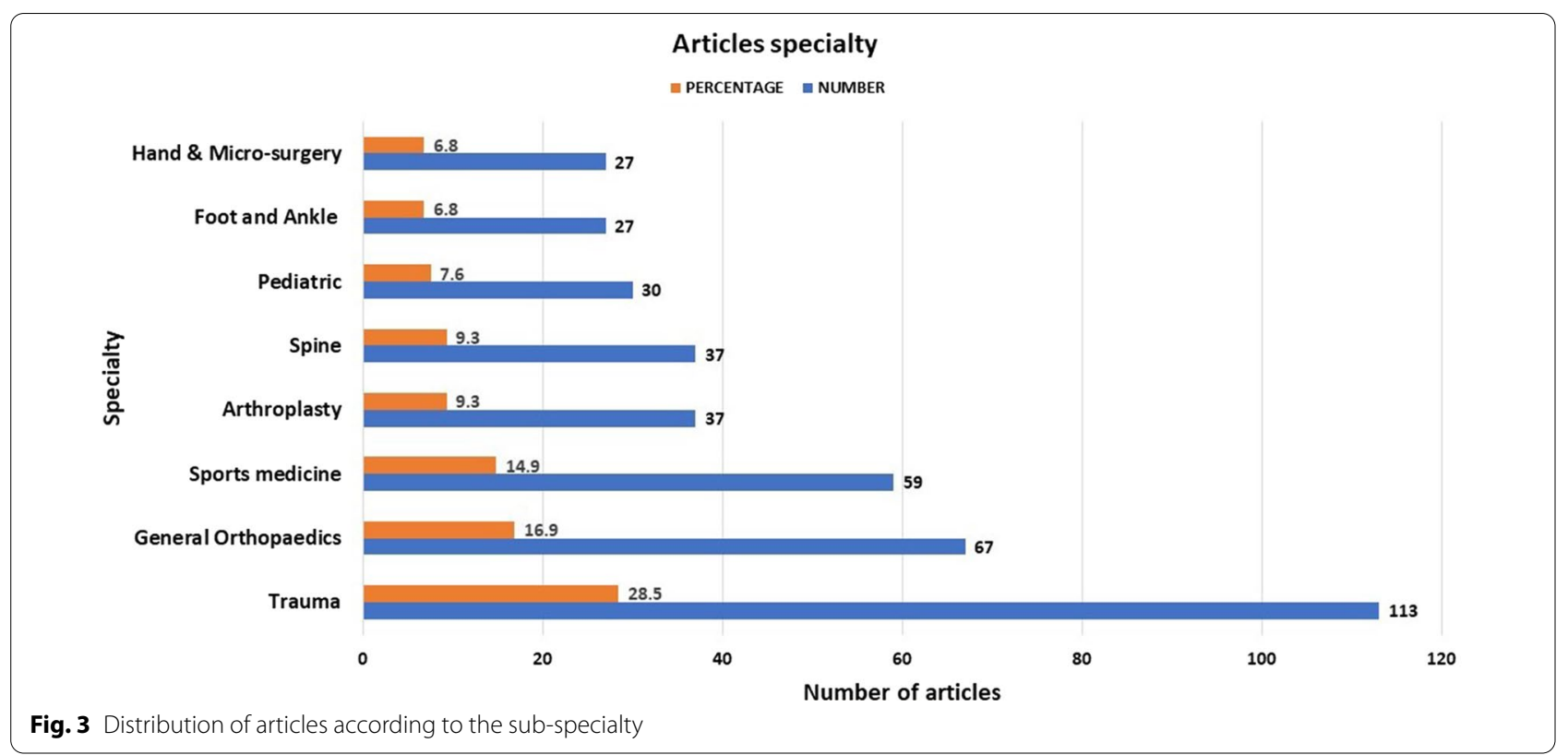

In a study by Siddiqi et al. (2016) evaluating the contribution to global publications from the North African countries in 2013, they found that the percentage of Egypt, Tunisia, Algeria, and Morocco contribution was $(0.48 \%),(0.16 \%),(0.12 \%)$, and $(0.08 \%)$ respectively, this contribution was considered very deficient when compared to the USA, which contributed alone by $19.2 \%$ of the total global share.

According to the recent update of the SCIMAGO journal and country ranking website (https://www.scima gojr.com/countryrank.php?area $=2700 \&$ region $=$ Africa $=$ Africa), the top five African countries regarding the production of scientific documents in medicine was South Africa, Egypt, Nigeria, Tunisia, and Morocco, with three of the five are North African countries.

In a study by Ghani et al. (2020) evaluating the scientific output from Low-/Low-Middle-Income (LIC/LMIC) Countries in nine high-impact general medicine and general global health journals over 30 months between 2014 to 2016, they found that although the African countries represented $24 \%$ of the global LIC/LMIC population, however, during the study period these countries showed a significant contribution as high as $49.9 \%$ of all publications.

The trend of increase in the number of authors contributing to the article had been proved and well described in the literature (Aboukhalil 2014; Camp and Escott 2013); most of the previous reports have shown an increase in the number of contributing authors in a single paper with a decline of the single authorship old trend (Aboukhalil 2014; Camp and Escott 2013). In a study by Ojerholm and Swisher-McClure (2015) after studying the authorship trends in the International Journal of Radiation Oncology, Biology, Physics, and Radiotherapy \& Oncology, they found that the mean number of authors per publication nearly doubled over 30 years period. In the study by Dynako et al. (2020), they found a high number of contributing authors in the American Journal of sports medicine (AJSM) and the Arthroscopy journal of a mean of 4.6 and 4.3 authors per article, respectively. The mean number of authors was found to be 5.8 per article in the study by Schrock et al. (2016) evaluating the authorship trends in the AJSM in 2014. In the current study, we found that the comments trend is single authorship representing $40.6 \%$ of total publications with a mean of $2 \pm 1$ authors per article, which is considered lower than the reported trends in the literature.

In the study by Schrock et al. (2016), they found that there is a diversity in the medical degree of the first author, although authors with M.D. was the most contributing (67\%); however, authors with master's degree and a bachelor's degree (young researchers) contributed as $4.2 \%$ and $3.9 \%$ respectively, indicating the involvement of young researchers in the authorship, they also reported that author with a bachelor's degree were medical students at the time of submission. On the contrary, in the current study, nearly all the first authors (99\%) carried an M.D. degree versus $1 \%$ carrying a master's degree and no contributions from researchers carrying a bachelor's degree, which reflects the poverty of young researchers contribution in the scientific process in the EOJ. 
In a study by Lehman et al. (2017) evaluating the authorship trend in the Journal of Arthroplasty over 30 years period, they found that a significant increase in the average number of authors per article from 1986 to $2015,3.45$ to 4.98 respectively $(\mathrm{P}<0.001)$, a significant increase in the proportion of first authors with a bachelor's degree $(\mathrm{P}=0.001)$ which indicates incorporation of young researchers.

The trend of medical student authorship in some journals was attributed to the increased competition among residency programs, as being involved in research activities will give them extra credit (Schrock et al. 2016).

Most of the articles in the current study were published from academic centers (the top 10 contributing institutions were an academic center and represented about $87.7 \%$ of all publications) with feeble contribution from governmental institutions; more contribution from academic centers was also reported in the study by Schrock et al. (2016) with a trend to increase over the study period.

In the study by Dynako et al. (2020) comparing the bibliometric characteristics of the AJSM to the Arthroscopy journal, they found that the mean number of institutions contributing to the articles was $2.5 \pm 1.8$ and $2.4 \pm 1.4$ of the two journals respectively, while in the current study cooperation between different institutions was only reported in $7.3 \%$ of the articles with a mean number of institutions contributing to the articles was $1.1 \pm 0.3$. The incorporation of different institutions in the research work has some advantages, including expertise exchange, collaboration to solve a particular problem, and the increase in research productivity (Parker and Kingori 2016; Sugimoto et al. 2013; Zeng et al. 2016).

In the current study, we found that the total international contribution to the journal was $5.3 \%$, articles where all the authors were part of an international group represented only $3.5 \%$, which was very low prevalence compared to other studies. In the study by Schrock et al., they reported an increasing trend in the contribution of international authors to the publications in the (AJSM) (Schrock et al. 2016).

Camp and Escott (2013) after investigating the orthopedic literature authorship characteristics between 1949 to 2009 , besides the increase in the mean number of authors (from 1.6 to 5.1 over the 60 -year), they also found an increase in the number of international institutions contribute to publications.

Cvetanovich et al. (2015), Modi et al. (2008) discussed the growth of the Internet, increased recognition and circulation of American journals abroad, and increased influence of research published in American journals as reasons for the increased internationalization of the author groups. Collaboration between national or international institutions in scientific publications may be attributed to the advancement in internet technology, which allowed easy communications between authors from different locations (Parker and Kingori 2016; Zeng et al. 2016).

\section{There are some limitations to our study}

First, the data presented in the current study originated from evaluating only one journal in a specific specialty (Orthopedics), which may limit the generalizability of the data over other journals or specialties. Second, the journal did not provide the degree of other contributing authors, which, if present, may change the prevalence of young researcher's authorship. Third, we compared the results with what was reported mostly from the western world without comparing the results with other journals from the same part of the world where the socioeconomic and other factors may play a role in determining the results reported in the current study. Finally, the current study was designed to report results from one journal and not to perform a comparative study in which trends of more than one journal could be compared.

\section{Recommendation}

More incorporation of young researchers (medical students and young surgeons) in different journals in various specialties in our area of the world should be encouraged. Teaching and training on scientific research should be incorporated in the undergraduate and the postgraduate curriculums in our countries. Specific policies should be adopted to ensure that contribution of young researchers and the attraction of international authors to contribute to our journals should be encouraged.

\section{Conclusions}

The results of the current study revealed a deficiency in the contribution of young researchers in the authorship in an Egyptian specialized medical journal, with a low incidence of international contribution and poor national institution cooperation. The old trend of single authorship prevails in the articles published by the journal, with the first author position nearly occupied by senior researchers.

\section{Abbreviations \\ EOJ: Egyptian Orthopaedic Journal.; EOA: Egyptian Orthopaedic Association. LIC/LMIC: Low-/low-middle-income; AJSM: American journal of sports medi-} cine; M.D.: Doctor of medicine; JBJS: Journal of bone \& joint surgery.

\section{Acknowledgements}

Not applicable.

\section{Authors' contributions}

AAK carried out the Study conception and design, ASE and AES carried out data acquisition, AAK carried out analysis and interpretation of data. All 
authors drafted the manuscript, and designed the figures, AAK did the critical revision. All authors discussed the results and commented on the manuscript. All authors read and approved the final manuscript.

\section{Funding}

There is no funding source.

\section{Availability of data and materials}

All related data were reported within the manuscript.

\section{Declarations}

\section{Ethical approval and consent to participate}

This article does not contain any experimental studies with human participants or animals performed by any of the authors. Ethical approval was waived by the local Ethics Committee of our institution. Consent to participate is not applicable.

\section{Consent for publication}

Not applicable.

\section{Competing interests}

The authors declare that they have no competing interests.

\section{Author details}

${ }^{1}$ Orthopaedic and Traumatology Department, Qena Faculty of Medicine and University Hospital, South Valley University, Qena, Egypt. ${ }^{2}$ Qena Faculty of Medicine, South Valley University, Qena, Egypt.

Received: 3 November 2020 Accepted: 22 March 2021

Published online: 07 April 2021

\section{References}

Aboukhalil R (2014) The rising trend in authorship. Winnower 2:e141832 Al-Busaidi IS (2015) Trends and patterns in medical student research and publishing in New Zealand. N Z Med J 128(1425):116-118

Al-Busaidi IS, Al-Shaqsi SZ (2015) Students' contribution to the New Zealand Medical Journal: a 14-year review. N Z Med J 128(1412):47-52

Amankwah N, Park M, Gu A, Choi BG (2018) Trends in authorship demographics for manuscripts published in the American journal of cardiology. Am J Cardiol 122(7):1255-1259. https://doi.org/10.1016/j.amjcard.2018.06.026

Camp M, Escott BG (2013) Authorship proliferation in the orthopaedic literature. J Bone Joint Surg Am 95(7):e44. https://doi.org/10.2106/JBJS.L.00519

Chow DS, Ha R, Filippi CG (2015) Increased rates of authorship in radiology publications: a bibliometric analysis of 142,576 articles published worldwide by radiologists between 1991 and 2012. AJR Am J Roentgenol 204(1):W52-57. https://doi.org/10.2214/AJR.14.12852

Cvetanovich GL, Fillingham YA, Harris JD, Erickson BJ, Verma NN, Bach BR Jr (2015) Publication and level of evidence trends in the American Journal of Sports Medicine from 1996 to 2011. Am J Sports Med 43(1):220-225. https://doi.org/10.1177/0363546514528790

Dotson B, McManus KP, Zhao JJ, Whittaker P (2011) Authorship and characteristics of articles in pharmacy journals: changes over a 20-year interval. Ann Pharmacother 45(3):357-363. https://doi.org/10.1345/aph.1P610

Dynako J, Owens GW, Loder RT, Frimpong T, Gerena RG, Hasnain F, Snyder D, Freiman S, Hart K, Kacena MA, Whipple EC (2020) Bibliometric and authorship trends over a 30 year publication history in two representative US sports medicine journals. Heliyon 6(3):e03698. https://doi.org/10 1016/j.heliyon.2020.e03698

Emery E (2019) Bibliometric analysis of neurosurgery publications in France. Neurochirurgie 65(1):7-13. https://doi.org/10.1016/j.neuchi.2018.08.006
Ghani M, Hurrell R, Verceles AC, McCurdy MT, Papali A (2021) Geographic, subject, and authorship trends among Imic-based scientific publications in high-impact global health and general medicine journals: a 30-month bibliometric analysis. J Epidemiol Glob Health 11(1):92

Khalifa AA, El-Hawary AS, Sadek AE, Ahmed EM, Ahmed AM, Haridy MA (2021) Comparing the gender diversity and affiliation trends of the authors for two orthopaedics journals from the Arab world. J Taibah Univ Med Sci 16(1):1-8. https://doi.org/10.1016/j.jtumed.2020.12.008

Lehman JD, Schairer WW, Gu A, Blevins JL, Sculco PK (2017) Authorship trends in 30 years of the journal of arthroplasty. J Arthroplasty 32(5):1684-1687. https://doi.org/10.1016/j.arth.2016.11.037

Modi P, Hassan A, Teng CJ, Chitwood WR Jr (2008) "How many cardiac surgeons does it take to write a research article?": seventy years of authorship proliferation and internationalization in the cardiothoracic surgical literature. J Thorac Cardiovasc Surg 136(1):4-6. https://doi.org/10.1016/j. jtcvs.2007.12.057

Ojerholm E, Swisher-McClure S (2015) Authorship in radiation oncology: proliferation trends over 30 years. Int J Radiat Oncol Biol Phys 93(4):754-756. https://doi.org/10.1016/j.jijobp.2015.07.2289

Parker M, Kingori P (2016) Good and bad research collaborations: researchers' views on science and ethics in global health research. PLoS ONE 11(10):e0163579. https://doi.org/10.1371/journal.pone.0163579

Reich MS, Shaw J, Barrett I, Goldberg VM, Schnaser E (2014) Level of evidence trends in the journal of bone and joint surgery, 1980-2010. lowa Orthop J 34:197-203

Rifkin WJ, Yang JH, DeMitchell-Rodriguez E, Kantar RS, Diaz-Siso JR, Rodriguez ED (2020) Levels of evidence in plastic surgery research: a 10-year bibliometric analysis of 18,889 publications from 4 major journals. Aesthet Surg J 40(2):220-227. https://doi.org/10.1093/asj/sjz156

Russell AF, Loder RT, Gudeman AS, Bolaji P, Virtanen P, Whipple EC, Kacena MA (2019) A bibliometric study of authorship and collaboration trends over the past 30 years in four major musculoskeletal science journals. Calcif Tissue Int 104(3):239-250. https://doi.org/10.1007/s00223-018-0492-3

Schrock JB, Kraeutler MJ, McCarty EC (2016) Trends in authorship characteristics in the American journal of sports medicine, 1994 to 2014. Am J Sports Med 44(7):1857-1860. https://doi.org/10.1177/0363546516639955

Siddiqi A, Stoppani J, Anadon LD, Narayanamurti V (2016) Scientific wealth in Middle East and North Africa: productivity, indigeneity, and specialty in 1981-2013. PLoS ONE 11(11):e0164500. https://doi.org/10.1371/journal. pone. 0164500

Stain SC, Hiatt JR, Ata A, Ashley SW, Roggin KK, Potts JR, Moore RA, Galante JM, Britt LD, Deveney KE, Ellison EC (2013) Characteristics of highly ranked applicants to general surgery residency programs. JAMA Surg 148(5):413-417. https://doi.org/10.1001/jamasurg.2013.180

Sugimoto CR, Thelwall M, Lariviere V, Tsou A, Mongeon P, Macaluso B (2013) Scientists popularizing science: characteristics and impact of TED talk presenters. PLoS ONE 8(4):e62403. https://doi.org/10.1371/journal.pone. 0062403

Tilak G, Prasad V, Jena AB (2015) Authorship inflation in medical publications. Inquiry. https://doi.org/10.1177/0046958015598311

Zeinoun P, AkI EA, Maalouf FT, Meho LI (2020) The Arab region's contribution to global mental health research (2009-2018): a bibliometric analysis. Front Psychiatry 11:182. https://doi.org/10.3389/fpsyt.2020.00182

Zeng XH, Duch J, Sales-Pardo M, Moreira JA, Radicchi F, Ribeiro HV, Woodruff TK, Amaral LA (2016) Differences in collaboration patterns across discipline, career stage, and gender. PLoS Biol 14(11):e1002573. https://doi. org/10.1371/journal.pbio.1002573

\section{Publisher's Note}

Springer Nature remains neutral with regard to jurisdictional claims in published maps and institutional affiliations. 